\title{
Erratum zu: Das deutsche Gesundheitssystem - Mängel, Defizite und Perspektiven
}

Edmund A. M. Neugebauer

Die korrigierte Version dieses Kapitels ist verfügbar unter: DOI 10.1007/978-3-662-48081-6_1 


\section{Erratum zu:}

Kapitel 1 in: J. Jerosch, C. Linke (Hrsg.), Patientenzentrierte Medizin in Orthopädie und Unfallchirurgie

DOI 10.1007/978-3-662-48081-6_1

Wir machen darauf aufmerksam, dass die jetzt zur Verfügung gestellte Fassung sich von der zunächst veröffentlichten Fassung unterscheidet. Ursache dafür ist die ursprüngliche Abbildung 1.1, die aus urheberrechtlichen Gründen ausgetauscht werden musste. 